\title{
O ROMANCE BRASILEIRO E O PERIODISMO
}

\author{
Rosana Cássia Kamita* \\ Universidade Federal de Santa Catarina
}

Resumo: A literatura brasileira em geral - e o gênero romance em particular - sempre estabeleceram fortes vínculos com o periodismo, seja no sentido de veiculação e divulgação das manifestações literárias, seja como espaço para reflexão sob as perspectivas da história, crítica e teoria da literatura. Assim, serão destacadas no texto essas relações entre o gênero romance e os periódicos, pontuando momentos relevantes dos séculos XIX, XX e XXI no Brasil.

Palavras-chave: literatura brasileira. Romance. Periodismo

Em 1836, em Paris, o jornalista Émile Girardin procurava opções para aumentar a venda de La Presse, seu jornal, e colocou em prática uma ideia original e de grande sucesso: publicar, em capítulos, as obras de alguns romancistas. Essas histórias obtiveram êxito apelando para as intensas emoções, lágrimas e impedimentos à concretização do amor. Não se esperava de seus leitores aprofundamentos literários, mas destinava-se a uma leitura de fruição, através de narrativas que despertassem o interesse e que os fizessem aguardar o próximo número com novidades e revelações de mistérios deixadas propositadamente em suspenso no capítulo anterior.

Esse era o romance-folhetim, uma fórmula de sucesso que em sua trajetória de expansão chegou ao Brasil. Conforme aponta José Ramos Tinhorão, em Os romances em folhetins no Brasil (1996), os folhetins foram traduzidos do francês e "publicados com regularidade em jornais brasileiros, principalmente no Rio de Janeiro, ainda na década de 1830”. Mais tarde, brasileiros passaram a escrever e publicar suas obras em periódicos.

Esta obra está licenciada sob uma Licença Creative Commons.

\footnotetext{
* Possui graduação em Letras pela Universidade Estadual de Londrina (1990), mestrado em Letras pela Universidade Estadual de Londrina (2002) e doutorado em Literatura pela Universidade Federal de Santa Catarina (2004). Professora Adjunta da Universidade Federal de Santa Catarina, na Graduação em Letras e na Pós-Graduação em Literatura. Tem experiência na área de Letras, com ênfase em Literatura, atuando principalmente nos seguintes temas: literatura brasileira e estudos comparados entre literatura e cinema.
} 
As histórias tinham como objetivo prender o leitor para que acompanhasse o desenrolar da narrativa a cada publicação, alguns capítulos vinham inclusive com pontilhados, para serem recortados e, ao final, a história estaria completa. O compromisso maior, naturalmente, era aumentar o número de exemplares de periódicos vendidos, e os escritores não pouparam esforços para alcançar essa meta.

O que se percebe é que a popularidade dos folhetins se devia, em parte, a fatores que a princípio o desqualificariam, como o sentimentalismo, personagens estereotipados, interesse por situações dramáticas, soluções trágicas, e ainda destituído de debate crítico em relação às injustiças sociais, certas regras de moral e comportamento, em uma tendência a apresentar essas questões de maneira complacente. Entre as décadas de 1830 a 1840, o Brasil possuía um comércio de livros ainda reduzido e a linha representada pelo folhetim influenciaria tanto o gosto dos leitores quanto os próprios romancistas brasileiros.

O folhetim oferecia muitas técnicas que poderiam ser praticadas pelos escritores, independentemente de suas obras serem publicadas ou não em jornais. Dentre as opções, estaria a possibilidade de alternar momentos de tensão com sequências mais leves, montar histórias paralelas, dispor os capítulos de forma que não continuassem no ponto onde o capítulo anterior havia parado, deixar um "gancho" para um capítulo posterior. Os exemplos de romances publicados em folhetins seriam vários, mas podemos citar $O$ tronco do ipê (1871), de José de Alencar, Inocência (1872), de Taunay, Helena (1876), de Machado de Assis.

A experiência com os folhetins no Brasil foi bastante relevante e temos um representante do folhetinesco, José de Alencar, pensando sobre o gênero romance em Como $e$ porque sou romancista (1873), livro no qual dirige sua verve para as relações estabelecidas com o romanesco. Nessa obra, o autor traça um painel sobre a literatura e a leitura na época, em um período no qual o romance começava a ocupar um maior espaço nas bibliotecas. A incipiência do gênero e a emoção dos leitores se tornaram ecos que soam muito distantes da atual produção, mas colaboram para a compreensão do papel exercido pelas narrativas, que se altera ao longo do tempo, porém permanece justamente por sua capacidade de transformação.

Essa obra se constitui em registro sobre o gênero no Brasil pela ótica de um de seus maiores referenciais, em uma espécie de "autobiografia literária". Nesse relato em forma de carta, o autor menciona a predileção "pela forma literária do romance". Em suas reminiscências literárias, Alencar conta sobre as sessões de leitura realizadas na época. Dentre essas, uma se destaca, na qual ele leu “com expressão uma das páginas mais comoventes da 
nossa biblioteca", levando às lágrimas as senhoras que o ouviam e ele mesmo, momento no qual recebem a visita de um padre, o qual se alarmou com a cena, imaginando que houvesse ocorrido alguma desgraça.

Rachel de Queiroz, parente distante de Alencar, conta no prefácio de Ubirajara (1874), romance do escritor, um episódio que dialoga com as memórias literárias antes referidas. Em um desses serões de leitura, o romancista leu os manuscritos inéditos de $O$ Guarani (1857), o qual terminava com um incêndio e a morte de todos, inclusive Peri e Ceci. Porém, as primas que ouviam esse final ficaram tristíssimas com o destino do casal e rogaram a ele para que os salvasse. E então "o primo José comoveu-se e prometeu escrever um desenlace feliz". Como virtuose das peripécias romanescas, o escritor criou o final que se tornou clássico, com a enchente, a palmeira providencial e o casal que "some no horizonte". Talvez as parentas não tivessem ficado de todo satisfeitas, ao menos, porém, no lugar da certeza da morte dos protagonistas, restava o consolo da dúvida quanto a isso.

Outra figura de destaque foi o escritor Machado de Assis, agudo observador da sociedade e que avançou em relação ao ufanismo nacionalista anterior, tentando apresentar um Brasil a partir de suas contradições. O autor sempre se manteve bem próximo ao periodismo, através da publicação de folhetins e também de crônicas e crítica literária. Um exemplo a ser citado nesse sentido é o texto "Notícia da atual literatura brasileira. Instinto de nacionalidade", publicado originalmente em 1873, no periódico O Novo Mundo. O periódico O Novo Mundo foi veiculado entre 1870 e 1879, seu fundador e redator foi José Carlos Rodrigues, brasileiro residente nos Estados Unidos. Além de Machado de Assis, há o registro da colaboração de outros escritores, como Sousândrade.

O texto de Machado examina a literatura "atual" da época (1873), nos momentos finais da estética romântica (atente-se que o romance considerado marco inaugural do Realismo no Brasil é justamente de autoria de Machado de Assis, Memórias Póstumas de Brás Cubas, publicado em folhetins em 1880 e em livro em 1881). Suas reflexões partem do princípio da nacionalidade expressa nas obras em diferentes gêneros, destacando o romance, a poesia e o teatro. Em relação ao gênero romance, objeto de atenção deste texto, o mesmo é considerado por Machado o gênero mais apreciado dentre todos. Mais especificamente no caso brasileiro, o autor pondera sobre o destaque à "cor local”, ou seja, ele percebe um certo excesso no recurso da descrição em detrimento às "qualidades de observação e análise". Sobre a reunião de obras publicadas, o escritor aponta: “[...] conserva-se aqui no puro domínio de imaginação, desinteressada dos problemas do dia e do século, alheia às crises 
sociais e filosóficas." Percebe-se, portanto, pela passagem anterior, sua preocupação com o gênero romance em relação com o que ele considera "a nossa adolescência literária". O autor reconhece as limitações do romance no momento, mas mantém uma postura otimista e finaliza destacando: "Nem todos os livros, repito, deixam de se prestar a uma crítica minuciosa e severa, e se a houvéssemos em condições regulares, creio que os defeitos se corrigiriam, e as boas qualidades adquiririam maior realce."

No século XX os periódicos foram muito importantes para a veiculação das novas ideias, em especial sob a perspectiva do movimento modernista, o qual viria de fato trazer a marca literária do presente, considerando-se o marco cronológico de 1922, com a realização da Semana de Arte Moderna. Um dos periódicos veiculados nesse período foi a Revista Klaxon - Mensário de Arte Moderna, cujo número 1 foi publicado em maio de 1922, em São Paulo. O periódico assim se apresenta a seus leitores:

\begin{abstract}
A lucta começou de verdade em princípios de 1921 pelas columnas do "Jornal do Commercio" e do "Correio Paulistano" Primeiro resultado : "Semana de Arte Moderna" - espécie de Conselho Internacional de Versalhes. Como este, a Semana teve sua razão de ser. Como elle: nem desastre, nem triumpho. Como elle: deu fructos verdes. Houve erros proclamados em voz alta. Pregaram-se idéias inadmissíveis. E' preciso reflectir. E' preciso esclarecer. E' preciso construir. D'ahi, KLAXON.
\end{abstract}

E KLAXON não se queixará jamais de ser incomprehendido pelo Brasil. O Brasil é que deverá se esforçar para comprehender KLAXON.

(In: KLAXON, $\mathrm{n}^{\circ}$ 1, São Paulo, 1922 - mantida a grafia original - Obra Digitalizada, Brasiliana Digital - USP).

Klaxon é uma espécie de buzina de automóvel, o que nas época remetia à ideia de modernidade e vanguarda. Um dos objetivos da revista era divulgar os principais conceitos da estética modernista, com a colaboração de muitos escritores e intelectuais, os quais procuravam colocar o Brasil no "mapa" do Modernismo. A crítica ao antigo foi explicitada no número inaugural da revista: "Século 19 - Romantismo, Torre de Marfim, Symbolismo. Em seguida o fogo de artificio internacional de 1914. Ha perto de 130 annos que a humanidade está fazendo manha. A revolta é justíssima. Queremos construir a alegria.” (Idem)

Além das críticas ao que se considerava ultrapassado, a revista veiculava ainda as próprias produções literárias modernistas, de autores como Menotti Del Picchia, Guilherme de Almeida e M. de A. (Mário de Andrade), este último, um dos líderes do movimento modernista no Brasil.

Assim como Klaxon, uma publicação relevante no século XX foi a Revista de Antropofagia, a qual foi veiculada entre 1928 e 1929. O número 3 da revista, datado de julho de 1928, traz, dentre outros destaques, o poema "No meio do caminho", do então jovem poeta 
Carlos Drummond de Andrade, a dilvulgação do novo livro de Antônio de Alcântara Machado, Laranja da China, e previsão de lançamento de Macunaíma, de Mário de Andrade. Ou seja, dentro da perspectiva adotada para este texto, destaca-se o papel fundamental exercido pelo periodismo para a literatura brasileira, pois são espaços para a disseminação de manifestações literárias e reflexão sobre os rumos dessa literatura.

Não é o objetivo aqui "mapear" a conexão entre o periodismo e o romance brasileiro, mas destacar alguns momentos relevantes e que se mostrem referenciais para a discussão do tema. Assim, a abordagem agora recairá sobre o presente, enfocando a literatura brasileira atual, considerando o século XXI como paradigmático para a literatura brasileira em geral e para o gênero romance em particular.

Segundo Tânia Pellegrini, os anos 90 e início do século XXI apresentam uma tendência "à exacerbação da violência", "tanto as narrativas literárias quanto as audiovisuais". Essa ênfase chegou ao ponto de ser considerada como um traço caracterizador dessas diferentes linguagens, com o paradigma maior representado por Rubem Fonseca e outros escritores que também escrevem nessa vertente, trabalhando com a temática da violência em uma fronteira sutil, a de ser possibilidade de denúncia ou puro espetáculo e banalização. A autora afirma que o realismo e o naturalismo seriam revitalizados nesse novo cenário, porém "com tintas mais sombrias" e "ancorados numa única matéria bruta, fértil e muito real: a cidade cindida".

A ficção brasileira do século XXI apresenta alguns contornos e características ao mesmo tempo em que se mostra ainda em formação, difusa em suas várias potencialidades, o que incentiva seu estudo. Karl Erik Shollhammer destaca a relação que o escritor contemporâneo pode estabelecer com a realidade histórica, inclusive no sentido de intervir sobre essa realidade, com toda a implicação que disso advém, uma vez que no contexto deste século permanecem antigas questões, em especial as que se referem ao setor econômicosocial. O que se depreende a partir disso é o fato de que a literatura se reveste de um teor social, no qual os escritores possuem um papel para além do trabalho de criação. O romance é um gênero referencial devido ao seu caráter livre e multiforme, com a intensa capacidade de se modificar ao longo do tempo, adaptando-se a diferentes tempos e lugares. Nesse sentido, a postura adotada por alguns escritores torna-se compreensível, pois podemos pensar que os mesmos dão continuidade a uma espécie de tradição, na qual se considera a intervenção da literatura na sociedade como ferramenta de denúncia e conscientização. Pelas leituras e pesquisas até o momento realizadas, é possível afirmar que essa tendência se mantém no 
início deste século e se constitui em um dos parâmetros pelos quais se pode basear a análise dos romances elencados.

O romance é um gênero híbrido, em constante transformação, ora considerado como manifestação menor, ora visto como possuidor de um caráter político com atuação direta na sociedade. No século XXI, o que podemos adiantar é que sua capacidade de transformação se mantém, com propostas diversas, algumas retomando características de épocas anteriores, outras, mantendo-se em consonância com a tônica do final do século XX, com ênfase à violência.

Assim, destaca-se nesse momento a Revista Anuário de Literatura, veiculada em meio digital através do Portal de Periódicos da UFSC. Ao se trabalhar com a literatura atual, ainda não há um distanciamento temporal que propicie um número ampliado de livros que abordem o assunto. Portanto, os periódicos cumprem uma função especial, pois sua periodicidade geralmente é semestral, especialmente através de artigos, o que aproxima o pesquisador de literatura produzida no século XXI, por exemplo, com a dimensão teóricocrítica de sua produção. Ao mesmo tempo em que se destaca pela rapidez de publicação, há também o crivo de qualidade expresso pela avaliação feita através de Conselho Consultivo.

Outro aspecto importante a ser abordado é o fato de que existe um caminho sem volta em relação às possibilidades tecnológicas e ao uso da internet. Assim, os periódicos eletrônicos integram um cenário mais amplo, de pessoas que pesquisam na rede até mesmo de maneira mais intensa do que nas próprias bibliotecas. $\mathrm{O}$ acesso é mais ágil e, em grande parte, gratuito.

Esse enfoque pode ainda reverberar sobre a autoria acadêmica, que enseja a produção de textos de acordo com certa demanda, uma expectativa por parte dos pares e pos parte dos leitores em geral. Assim, determinados assuntos tornam-se referenciais em um período e subsidiários em outro, dependendo dos próprios pesquisadores e da influência que exercem uns sobre os outros, no fortalecimento (ou fragilidade) de determinadas linhas de pensamento. Conceitos se destacam enquanto outros caem na obscuridade. Ou seja, os periódicos possuem um papel político, de legitimação de determinados discursos em detrimento de outros. A veiculação de conceitos e ideias perpassa por um viés de predominância acadêmica na superfície e política na essência.

O espaço para a veiculação de periódicos tem se ampliado bastante, como se pode verificar através do novo periódico do Curso de Letras-Português: uox - Revista Acadêmica do $D L L V$. Trata-se de uma revista voltada para a graduação, no sentido de estimular a 
iniciação científica através de publicações dos alunos do Curso de Letras-Português do Departamento de Língua e Literatura Vernáculas e também estabelecer diálogos com outros cursos de Letras e áreas afins.

Muitos seriam os periódicos a serem destacadados, mas o obejtivo foi o de estabelecer recortes que subsidiassem os elos entre o gênero romance e o periodismo. Desde sua gênese, o gênero romance estabelece um forte vínculo com o periodismo, o qual colaborou diretamente para o surgimento do romance assim como para a consolidação do gênero ao longo do tempo e mantém essa aproximação na atualidade, dinamizando as discussões sobre os novos autores e obras.

\section{Referências}

ALENCAR, José de. Como e porque sou romancista. Campinas: Pontes, 1990.

ASSIS, Machado de. "Notícia da atual literatura brasileira. Instinto de nacionalidade". In: $O$ Novo Mundo. Versão digitalizada acessada em http://www.onovomundo.net/ em novembro de 2012.[ Publicado originalmente em O Novo Mundo, 24/03/1873].

BAKHTIN, Mikail. Questões de literatura e de estética: a teoria do romance. São Paulo: Unesp, 1988.

BOSI, Alfredo. História Concisa da Literatura Brasileira. São Paulo: Cultrix, 1995.

CANDIDO, Antonio. Formação da literatura brasileira. Rio de Janeiro: Ouro sobre o azul, 2006.

KLAXON, $\mathrm{n}^{\mathrm{o}}$ 1, São Paulo, 1922. Obra Digitalizada, Brasiliana Digital - USP.

MEYER, Marlise. Folhetim: uma história. São Paulo: Companhia das Letras, 1996.

PELLEGRINI, Tânia. A imagem e a Letra: aspectos da ficção brasileira contemporânea. Campinas: Mercado das Letras; São Paulo: Fapesp, 1999.

Revista de Antropofagia, $\mathrm{n}^{\circ}$ 3, São Paulo, 1928. Obra Digitalizada, Brasiliana Digital - USP.

SCHOLLHAMMER, Karl Erik. Ficção Brasileira Contemporânea. Rio de Janeiro: Civilização Brasileira, 2009.

TINHORÃO, José Ramos. Os romances em folhetim no Brasil: 1830 à atualidade. São Paulo: Duas Cidades, 1994.

[Texto apresentado durante o evento em comemoração aos 20 anos da Revista: Anuário de Literatura, memórias em perspectiva, ocorrido em 28 de novembro de 2012] 


\section{The Brazilian romance and the periodism}

Abstract: The Brazilian literature in general - and the romance genre in particular - always established strong ties with periodism, either in the sense of propagation and dissemination of literary manifestations, whether as a space for reflection on the perspectives of history, criticism and theory of literature. So, these are highlighted in the text relations between the romance genre and periodicals relevant punctuating moments of the nineteenth, twentieth and twenty-first century in Brazil.

Keywords: Brazilian literature. Romance. Periodism.

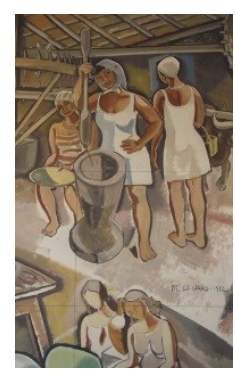

